\title{
Getting the picture... and the joke: The pictorial and the verbal in business cartoons
}

\author{
Pauline Tee Anderson
}

\section{OpenEdition}

\section{Journals}

Electronic version

URL: http://journals.openedition.org/asp/2273

DOI: $10.4000 /$ asp. 2273

ISBN: 978-2-8218-0382-4

ISSN: 2108-6354

Publisher

Groupe d'étude et de recherche en anglais de spécialité

Printed version

Date of publication: 31 December 2000

Number of pages: $349-362$

ISSN: 1246-8185

\section{Electronic reference}

Pauline Tee Anderson, « Getting the picture... and the joke: The pictorial and the verbal in business cartoons », ASp [Online], 27-30 | 2000, Online since 26 February 2011, connection on 01 May 2019. URL : http://journals.openedition.org/asp/2273 ; DOI : 10.4000/asp.2273

This text was automatically generated on 1 May 2019.

Tous droits réservés 


\title{
Getting the picture... and the joke: The pictorial and the verbal in business cartoons
}

\author{
Pauline Tee Anderson
}

1 There is a good case for including humorous material in the language teacher's toolbox. Firstly, it can be argued that humour competence should be one of the target skills of all language learners since laughter is a universal phenomenon and the humour ${ }^{1}$ likely to produce it can promote communication - or hinder it by its absence; this aspect of the target language and culture seems particularly important in the case of English, in view of the place occupied by -and attributed to- humour in the Anglo-Saxon world. Secondly, working on such material can be seen as a learning need, as the classroom anxiety which is especially marked among language learners (Tsui 1995: 87) can be reduced and even eliminated by laughter, whose role in inducing a state of relaxation has been underlined by researchers (e.g. Fry and Savin 1988 in Morreall, 1991). It goes without saying that a relaxed atmosphere is far more conducive to participation and learning than a tense one.

Why cartoons in particular? In my opinion, these documents are an excellent introduction to humour in a foreign language, not least because the vast majority associate verbal text and that well-known teaching aid, the picture. The aim of this article is to identify the different ways in which these two components interlock to produce a joke and to show how this relationship can have a bearing on the learning process, helping students in their efforts to acquire not only linguistic items but also facts about the target culture. Although the examples given will be of particular relevance to business English students, many of the issues discussed will be pertinent to other language learners.

3 However, before these questions are addressed, some general points need to be outlined. 


\section{The pictorial and the verbal in cartoons}

4

As Morin states, it is possible to transform cartoons into verbal texts but this would make them less amusing: "Le dessin est une plaque plus sensible au comique que le verbe" (1970: 131). It would also make them longer, whereas it is partly the conciseness of humour that gives it a greater impact than other forms of communication (Ziv 1979: 110). Cartoons are particularly economical thanks to their pictorial component, which also gives them immediacy.

Indeed, one of the skills of a cartoonist is to convey a wealth of information in a minimum of space: the joke will fall flat if we do not understand at once who the protagonists are, where they are, what they are doing, what they are feeling, and so on. Many of these details are transmitted solely by iconographic means but verbal information is sometimes added so that we know, for example, that the scene is taking place in the sales department of a firm (a graph with the heading SALES on the wall, a sign on the door, etc.) or at the customs (indicated on a panel suspended from the ceiling, for instance). Likewise, although his clothes and briefcase are sufficient to identify a businessman away from the office, the briefcase is labelled ACCOUNTANT, HOME SALES and so onwhen we need to know the exact nature of his work. If the cartoon refers to a particular current event or social trend, the device of the newspaper headline is often used. All these are examples of the 'anchorage' function of the linguistic text, which elucidates the reader and subtly directs him to the intended message (Barthes 1964: 44).

Only 12 of my corpus of 1194 business cartoons have no written text at all. Although purely pictorial cartoons can be seen as very impressive in that they require more invention on the part of the cartoonist than drawings accompanied by words, it can be considered that the absence of writing produces a more arid result: in order to go beyond the cliché in psychology, politics, social issues, etc., some verbal explanation is needed (Morin 1970: 112). This usually consists of the words of one of the protagonists, but in some cases the joke is contained in the written text incorporated into the drawing: for example, a bank in the Channel Islands not only has a CASH POINT, but also-in a dark alley - a STASH POINT, the latter being used by a furtive-looking gentleman (Appendix cartoon 1). In such cases, the cartoonist clearly has no other intention than to amuse the reader. 


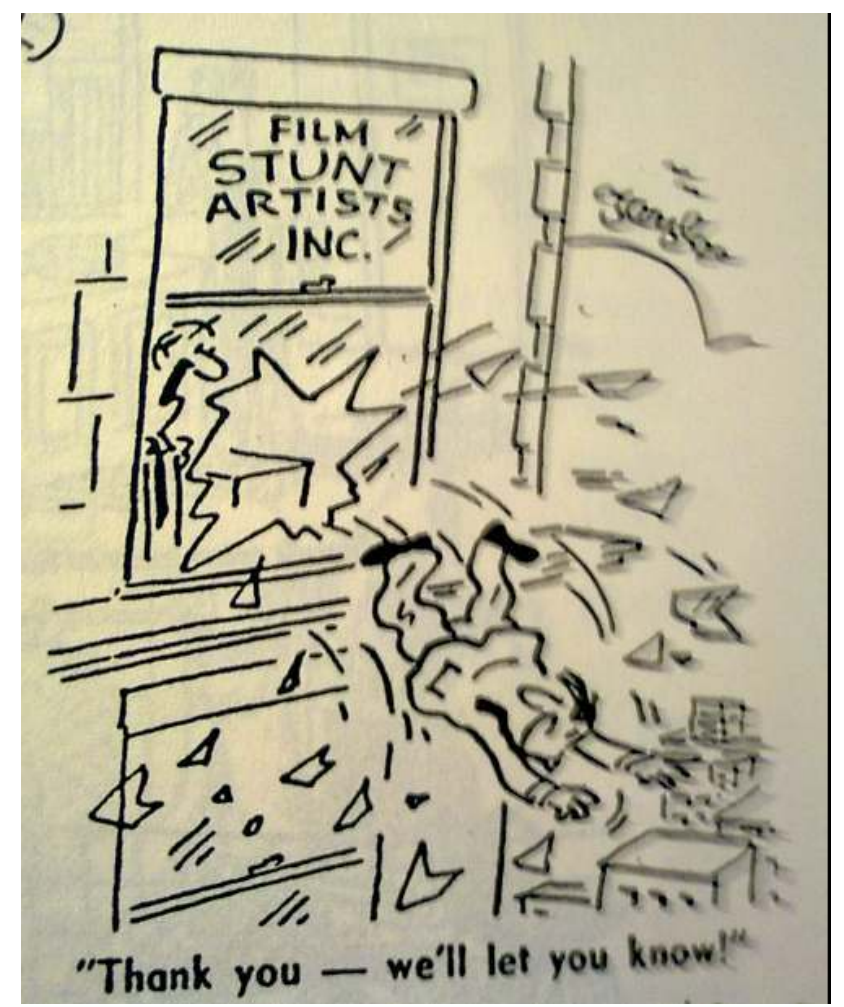

The Weekly News Cartoons (c) D.C.Thomson\&Co., Ltd Dundee Scotland

Analysis of document 2 shows how the picture and different forms of verbal text can interact in a cartoon. Here we see a man who has just smashed through a very high window and is plunging towards the ground. Has he been pushed? Has he fallen? Has he jumped? We know that this is a cartoon so we expect the incident to be treated in a lighthearted way but, without any verbal text, we would have no answers to these questions. However, the words on the window, FILM STUNT ARTISTS INC., which we see simultaneously, have the 'anchorage' function mentioned above and thus orient our interpretation: the protagonist must be a stuntman and the scene is no doubt connected with his work. The caption, consisting of the words of a man inside the building, "Thank you -we'll let you know !", both reveals the incongruity of the situation -there is no safety net- and provides that essential ingredient of any text, coherence: ${ }^{2}$ an interview has taken place and the candidate is demonstrating his skills. The action we are witnessing thus becomes a narrative. The humour comes largely from the contrast between the banality of the words and the dramatic event shown in the picture: the man is risking his life to land the job but still fails to impress. Yet we are amused. We cannot help smiling at the expression on the stuntman's face and the sight of him suspended in mid-air, a fact which -together with the improbability of his predicament- makes us see it as comic rather than tragic; the drawing therefore softens the cruelty of the interviewer's utterance.

This interaction of the pictorial and the verbal inherent in cartoons raises a question that interests researchers in the field: do people look at the illustration or the caption first? Whatever the case may be in an authentic situation, the two components can be artificially separated for teaching purposes. For instance, the illustration can be presented without the caption or with the key element of the joke removed (either part of 
the verbal text or, occasionally, part of the drawing), so that students can produce their own joke or complete the cartoonist's. This approach has three main advantages. Firstly, it gives learners the opportunity to develop their humour skills in English and to make their classmates laugh, which is a very encouraging reaction to obtain. Secondly, they are pleased and feel a sense of achievement when they produce the same or a similar caption to the original, which again has a positive effect on motivation. Thirdly, the delay can increase interest in the document as well as suspense, the latter tending to add to the humour of the joke when it is eventually revealed. It hardly needs to be mentioned that pleasure, motivation and interest are among the affective factors that are likely to encourage learning; however, it is perhaps less well known that humour has been demonstrated to promote comprehension and retention when it is linked to the concepts being taught (Kaplan and Pascoe 1977; Ziv 1988).

\section{From the neutral to the absurd: subjects for discussion}

9 The majority of researchers working on second language acquisition believe that producing the target language plays a crucial part in this process (McLaughlin 1987: 50), but arousing students' interest in a discussion is a problem familiar to many teachers. Cartoons can help here, since one of their great strengths as a teaching tool is their capacity to provoke reaction and therefore comment. ${ }^{3}$ If the cartoon in question concerns the students' field of study, it follows that they will be obliged to use target language, which could involve trying out terms that have just been introduced (perhaps with the help of the cartoon) and / or recycling items previously learnt.

In my experience, students generally have something to say about the incongruous events depicted, and enjoy exploring the psychology and motivations of the protagonists and attempting to account for their illogical behaviour (often producing equally incongruous and amusing 'clarifications' in the process). An extremely important point here is that most students do not look for just one 'solution'. The reason for this can be found in the link between humour and two ingredients of creativity, divergent thinking and originality, which has been established by researchers; for example, Ziv (1983) maintains that a humorous atmosphere and the fact that a teacher encourages humour 'liberate' learners from the constraints of convergent thinking (finding the one correct answer) and lead them to express unusual and even 'crazy' ideas. It therefore follows that the funnier students find a cartoon (the funniness usually being increased, as previously mentioned, if the punch-line is withheld), the more interpretations are likely to be produced. In the case of cartoons, this process is encouraged because there is often a 'residual incongruity' that is not resolved by the document itself (Forabosco 1992: 49) and, as the teacher cannot explain it any more than the students can, for once they are on an equal footing.

11 But how exactly does the nature of the illustration and its relationship with the verbal text affect what students have to say? 


\subsection{Neutral illustrations}

12 A large number of cartoons have illustrations that can be considered neutral, their role being simply to set the scene for the joke which is entirely contained in the caption. These show us at a glance that something amusing is going to happen, for instance, between a boss and a subordinate, an interviewer and a candidate or a bank clerk and a customer. ${ }^{4}$ Many of the illustrations that come into this category are in fact interchangeable, and could therefore give the impression that they have little potential for arousing students' interest. Yet this is not necessarily the case. Perhaps it would be more accurate to say that these interchangeable illustrations are relatively neutral since the very nature of caricature means that cartoon characters are seldom drawn in a totally neutral way: physical features tend to be larger than life, facial expressions and gestures are often exaggerated far beyond the norm and stereotypes such as the weasel-like salesman and the sexy secretary abound, the caption usually confirming the impression of dishonesty or stupidity given by the way they are drawn. Even these 'neutral' illustrations can therefore be sufficiently amusing, intriguing or irritating to arouse comment.

\section{Cartoon 3}

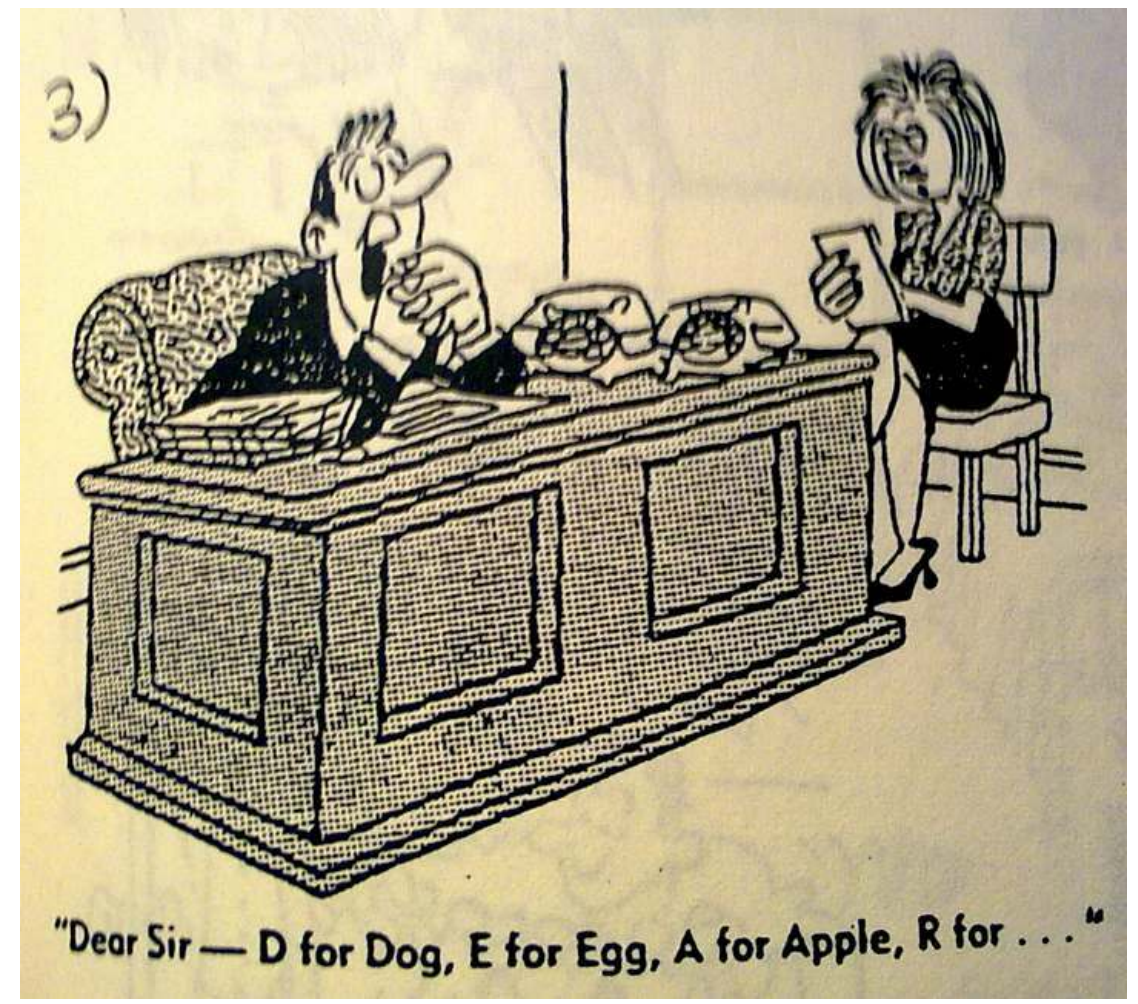

The Weekly News Cartoons (c) D.C.Thomson\&Co., Ltd Dundee Scotland

However, the appearance of the secretary taking dictation in cartoon $n^{\circ} 3$ is relatively realistic and the picture is unlikely to produce a reaction without the written text. But the boss's words ("Dear Sir -D for Dog, E for Egg, A for Apple, R for ...") can lead the students to question the neutrality of the picture: why is the secretary simply taking down the letter without the slightest hint of annoyance? Is she really so bad at her job 
that she cannot spell even simple words that she must have to write every day? And if this is the case, how is it that she has not been dismissed? In this cartoon, it is the very neutrality of the illustration which adds to the incongruity of the situation and therefore the remarks that students can make about it.

\subsection{Incongruous illustrations}

Surprise is one of the components of humour and this can be created by the illustration as well as the verbal text of a cartoon. The illustration in $n^{\circ} 4$ (see Appendix) is the sort of drawing that students immediately laugh at and have plenty to say about: a very sexy female employee has just smashed up a computer with an axe. This incongruous behaviour is 'explained' by the caption "I've opened your e-mail, Mr Brompton" in that we see the logic behind it (an envelope containing conventional mail is opened with a letter-opener; a computer containing electronic mail is opened with an axe) but this excess of logic produces a paradox. However, the questions and interpretations inspired by the illustration are not necessarily clarified by the caption although, at first sight, this appears to be the case: the young woman, far more interested in her clothes and make-up than in learning about new technology, seems to be yet another example of the 'stupid secretary' stereotype. But is she really? According to different students' suggestions, she may in fact know very well what she is doing and is taking revenge because she is angry with her boss, perhaps because she is the victim of sexual harassment or because he has not given her the pay rise or promotion she deserves; after all, why should women have to hide their femininity in order to be respected and taken seriously? Another possibility is that she has had enough of working on an old computer and feels that this is the only way to make her budget-conscious boss invest in a new one.

These proposals are interesting in that they reveal students' reactions to the numerous business cartoons that can be seen as derogatory to women. ${ }^{5}$ Far from accepting this, they tend to put forward interpretations that show the woman in a positive light and her boss in a negative one.

\subsection{Absurd illustrations}

16 Twenty-two of the cartoons in my corpus show situations that are completely absurd in that they defy the laws of nature. All but one of these involve animals acting like humans, for instance dogs signing letters ("Yours faithfully"), driving lorries loaded with timber ("He started by fetching the occasional stick and built up the business from there") or, aware of the necessity of being equal opportunities employers, interviewing cats for watchdog posts. ${ }^{6}$ In the world of cartoon logic, the written text accounts for the absurdity of these events and produces smiles and laughter but, in my experience, such documents do not tend to inspire comment.

This was not the case with the only cartoon of this type showing a human being: a businessman crawling across his office ceiling (cartoon 5, see Appendix). When the illustration was shown to a class of students, it produced loud laughter and gave rise to a wide variety of interpretations, ranging from the possibility that the man could be testing a new product enabling people to walk on ceilings, to the possibility that total madness results in gravity-defying abilities. Again, these suggestions testify to students' willingness to suspend their disbelief and enter into a 'playful' mode when encouraged to 
do so. The secretary's mundane words ("He doesn't seem to be at his desk") add to the humour of the document and also to the enigma: is she trying to protect her boss by hiding the fact that he has gone completely mad? Does she have to do this all the time? Is she mad too? Or perhaps she simply does not realise what is going on just above her head, which would put the spectator in the privileged -and amusing- position of knowing more than the protagonist. By opening the door to absurdity, this type of illustration invites learners to give free rein to their imaginations and venture into the realm of nonsense.

\section{Language points}

With the exception of $n^{\circ} 1,7^{7}$ the cartoons considered so far present no particular problems of comprehension for learners of English but this is not always the case: students will only be able to understand certain documents with the help of a dictionary or the teacher. Sometimes, however, the meanings of unknown terms and expressions can be inferred from the situation or, very often, the illustration, which therefore help students 'get the picture' as well as the joke.

The importance of the ability to infer has been stressed by researchers working in the field of L2 acquisition, for example those who have tried to identify the characteristics and strategies of good language learners. According to Stern, such learners look for the meaning of an utterance or a communicative act by all possible means, in particular by taking the context and situation into account (Cyr 1998 [1996]: 18). Likewise, Rubin considers that these learners use all the clues given by the situation, the non-verbal for instance, to infer the speaker's intention or the message (Cyr 1998 [1996]: 21-22). Moreover, in their Modern Language Aptitude Test (MLAT), Carroll and Sapon consider inference to be one of the abilities that indicate language learning aptitude (Cyr 1998 [1996]: 50). As inference is also one of the strategies used by good readers, many comprehension exercises are designed to encourage it; the following examples will show that cartoons can also help learners to develop this essential skill.

\subsection{Terms related to business}




\section{Cartoon 6}

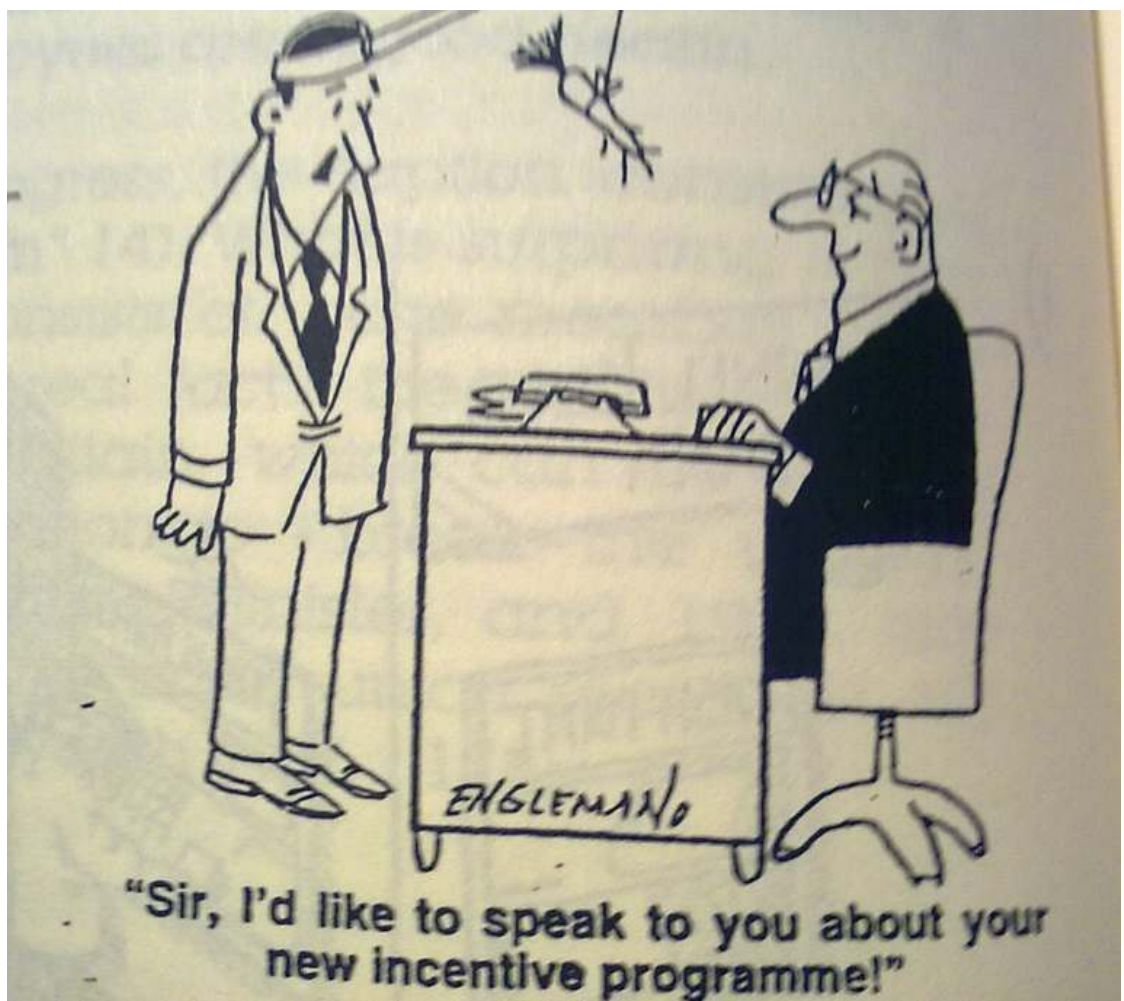

The Weekly News Cartoons (c) D.C.Thomson\&Co., Ltd Dundee Scotland

In cartoon 6, a worker says to his boss, "Sir, I'd like to speak to you about your new incentive programme!" On reading these words, many students will not know the term incentive programme but, thanks to the picture of the man wearing on his head a contraption to which a carrot is attached, so that it is dangling just in front of his eyes, learners can understand that the purpose of such a programme is to encourage people to work harder by offering them hope of a reward. 


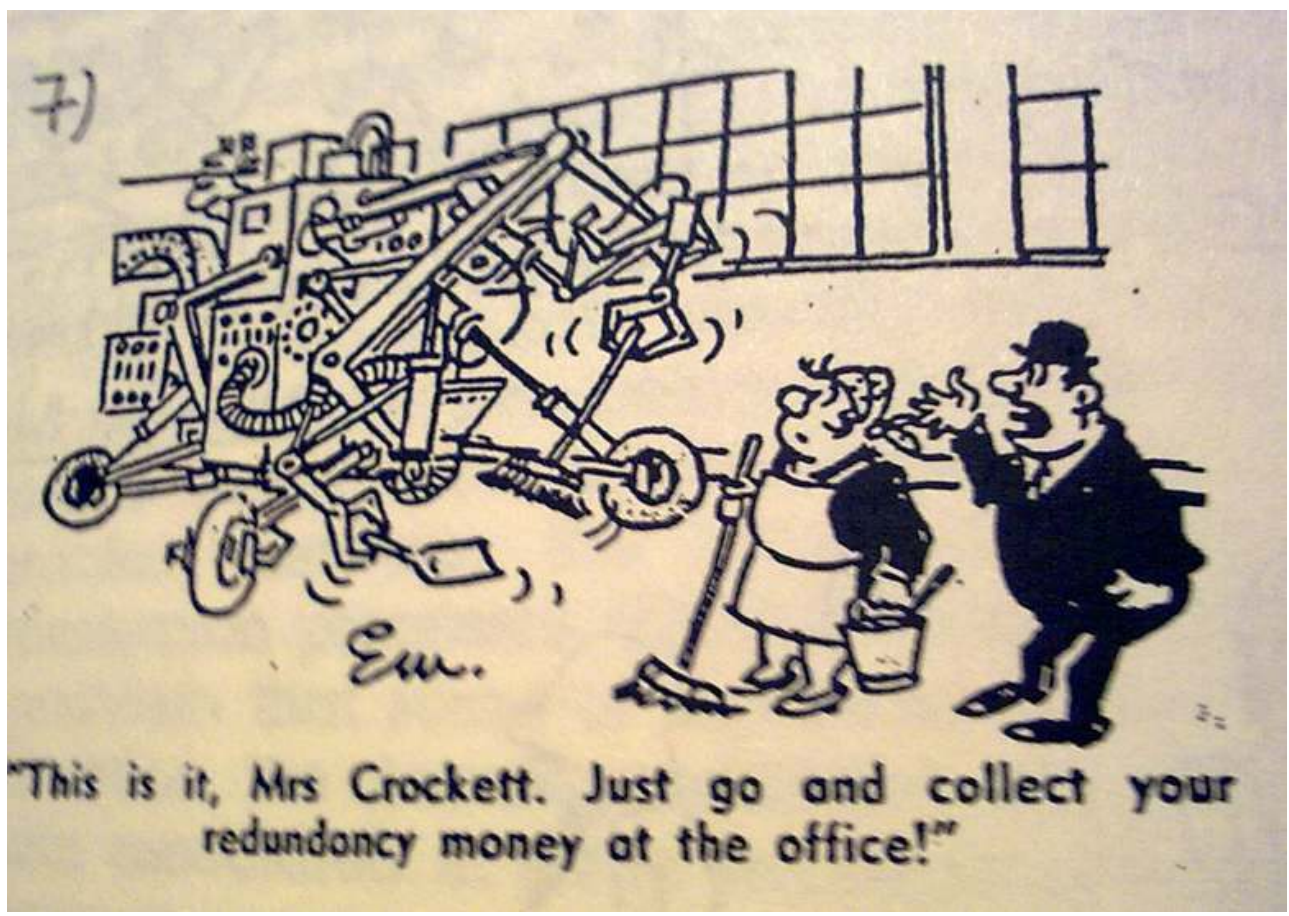

The Weekly News Cartoons (c) D.C.Thomson\&Co., Ltd Dundee Scotland

In cartoon 7, a manager is showing a cleaning lady a very large, highly sophisticated machine that is cleaning the firm's premises all on its own: "This is it, Mrs Crockett. Just go and collect your redundancy money at the office !". It is clear from this drawing that the robot can do the work of several people and that the woman is no longer needed, enabling students to infer the meaning of redundancy. An alternative approach would be to show the picture first so that the students see what is happening before they see the new word. The fact that the picture is so striking could also help learners remember the distinction between make redundant and dismiss (both of which can be translated by licencier), since it is clearly not the cleaner's fault that she is being told to leave the firm.

Another new term can be learnt from cartoon 8 (see Appendix). A man with an abacus on his knees says to the passenger sitting next to him on a plane, "State-of-the-art Chinese lap-top !" It is possible to infer the meaning of lap-top because his travelling companion can be seen using a lap-top computer, the fact that it is similarly shaped to the abacus establishing a parallel between the two devices. State-of-the-art is considerably more difficult but, if students are reminded that cartoons, like other forms of humour, are not always 'politically correct', some may infer that the protagonist is saying that his abacus would be considered very modern in China, in the same ways as his companion's lap-top is seen as very modern in western society. However, this is a case where most students would need guidance to help them fully decode the document.

\subsection{Colloquial terms and expressions}

As the captions of cartoons reproduce speech, many of them contain informal words and expressions that students often do not know and, again, the meanings of these can sometimes be inferred with the help of the picture. For instance, a zoo worker says to a 
colleague, "If we don't get that pay rise, I'm going to blow the lid off this crummy zoo!" $\left(n^{\circ} 9\right)$. The key to the joke (and to the meaning of the words) is in the picture: the two men are in a cage and are dressed as pandas. What sort of zoo is this? As it is clearly a poor quality establishment, learners are able to infer the general meaning of crummy and even propose a possible translation if they are asked to describe it in French (minable, lamentable). The idiomatic expression to blow the lid off something is more difficult. Students can see that the zoo worker is angry and can infer from the co-text ("If we don't get that pay rise....") that he is making a threat. What could he do to harm his employers? He could reveal the truth about what is happening (the correct meaning) but students could also imagine, because of the verb blow up, that he is planning to plant a bomb. Which is the more plausible? If they are encouraged to think about it, they are likely to realise that the idea of killing and maiming animals (or the workers' colleagues dressed as animals) is not very funny, even in the twisted world of cartoons, and to conclude that the first possibility is the more likely. Nevertheless, this document again shows the limits of inference and that, on occasions, learners will need confirmation from the teacher or a dictionary.

Cartoon 9

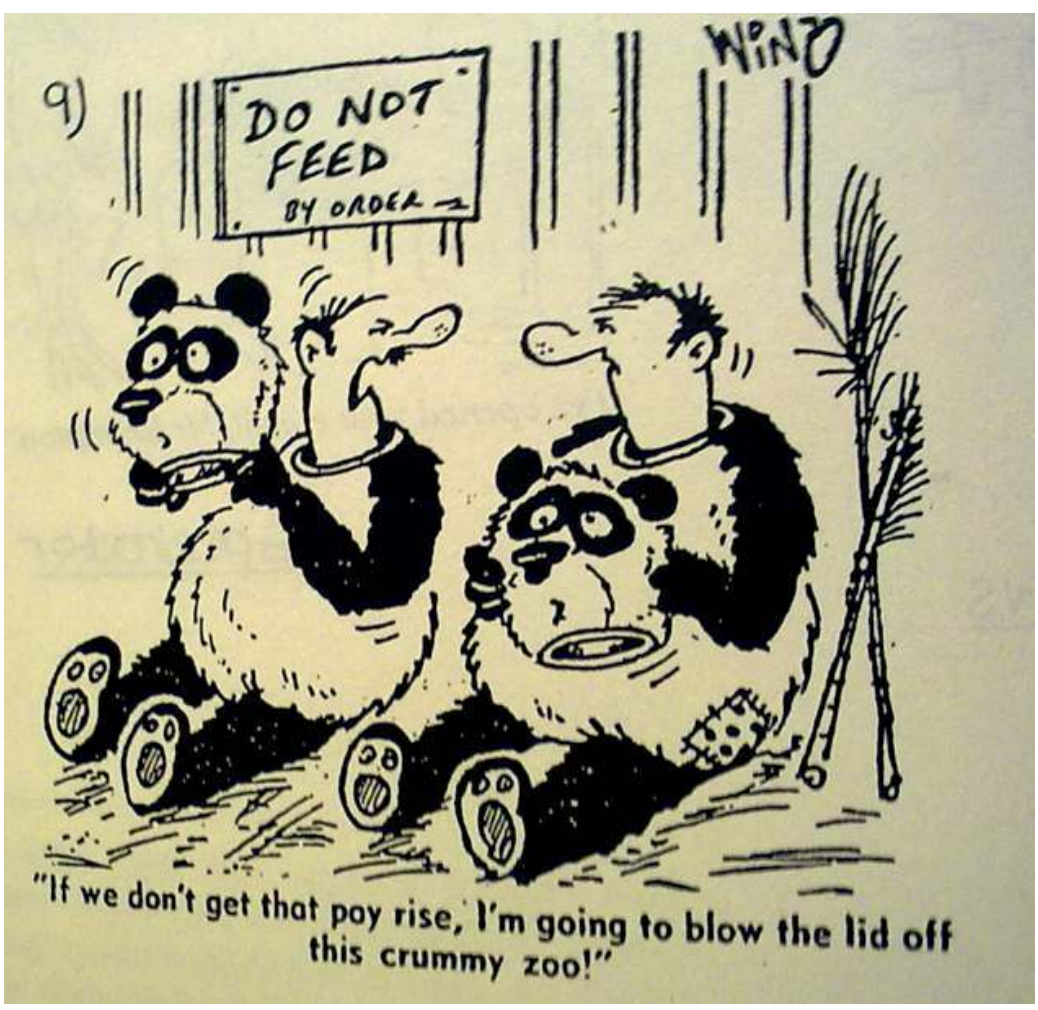

The Weekly News Cartoons (c) D.C.Thomson\&Co., Ltd Dundee Scotland

The meanings of two other expressions can be inferred by jokes based on in-trays and out-trays, a common device in business cartoons ${ }^{8}$. One office worker's trays are marked EASY COMEand EASY GO, a point which is 'explained' by the way their owner is depicted: he is working but the calm expression on his face and his loosened tie show us that he is extremely relaxed. His colleague's words "Well, I don't like his attitude!" do not in fact add anything to the joke. In another office, there are two empty trays labelled IN and ouT and a third one, overflowing with documents, marked COULDN'T CARE LESS; the owner of 
these trays is leaning back in his chair, smoking and doing no work at all, this state of affairs being clarified by a passing colleague “... and that's the boss's son!" Again, the caption is not essential to the joke but it provides a rational explanation for the employee's behaviour - and can lead to a discussion on the importance of having the right connections in business.

\subsection{The literal and the figurative}

Another frequent device of cartoonists is to play on the literal and the figurative meanings of an expression; very often, it is the drawing that shows the literal meaning and the verbal text which refers to the figurative meaning. However the two meanings are referred to, it is up to the reader to supply the figurative meaning but, if learners are not familiar with this, it is usually very difficult or even impossible for them to infer it. Such documents are therefore particularly suitable for an exercise for which students have access to a dictionary.

In cartoon 10 (see Appendix), a manager enters an office to find a member of his staff smiling happily at the chain of paper figures he has just cut out: "When I said we'll have to cut out some of this paper work, Fenton, I meant...!" Even if the verb cut out in the sense of eliminate is not familiar to the students, some will perhaps manage to infer what the boss meant for two reasons: firstly, there are two piles of documents on the employee's desk and, secondly, it is logical for firms to want to simplify procedures and thus reduce the amount of paper work that has to be carried out (filling in forms, writing letters and reports, etc.). However, it is also possible to think that the boss wants some of the documents to be shredded so, again, students who do their best to use their powers of inference will not necessarily find the right answer.

It is also possible for the verbal text to refer to the two meanings. In cartoon $\mathrm{n}^{\circ} 11$ ((see Appendix), a new pupil is being welcomed to the TARZAN ACTORS' TRAINING SCHOOL. The illustration is amusing in itself (the three men, in loin cloths, clearly have more brawn than brains), as is the idea that such a school could exist, but the whole joke is in the caption: "Johnny here will show you the ropes". In view of the strength of the schema produced by Tarzan + ropes, a mental image of these would-be Tarzans swinging around, practising their skills, is immediately conjured up (rather than a mental picture of Johnny simply showing the newcomer where the ropes are). However, students who do not know the figurative meaning of to show someone the ropes will not be able to go any further in decoding the joke, however developed their powers of inference; nevertheless, they could still find the cartoon funny for the reasons mentioned and some may suspect that a piece is missing from the puzzle and will look further. ${ }^{9}$

\section{Cultural information}

Whereas the documents studied so far simply tell a joke and were produced for no other reason than to make the reader smile, many cartoons reflect current events or social trends and some can be considered to be a serious comment on the issues concerned. The sociological nature of such documents makes them suitable for presenting information about the target culture. 
The picture of a couple leaving two toddlers among the inmates of Bob's Kennels is a striking one, as is the reason given in the caption: it is cheaper than day care $\left(n^{\circ} 12\right.$, see Appendix). Yet this apparently ludicrous situation in fact mirrors reality: the lack of organised day care in Britain is an all-too-real problem for parents who both work, and is compounded by the fact that children do not start school until they are five or nearly five; since they are in short supply, such facilities are also very expensive. Some firms therefore provide a crèche as a fringe benefit.

Another area where the State system is somewhat lacking is health care. At first glance, the scene depicted in cartoon 13 (see Appendix), which does not have a caption, appears to be perfectly normal: two men are in hospital. However, instead of having medical charts at the foot of their beds, they have credit cards. The lack of verbal message (the words MASTERCARD and VISA are purely for identification) no doubt has the enigmatic intention mentioned by Barthes (1964: 43): the cartoon is much more effective because the reason for this incongruity is left unresolved and is not 'explained' by a caption such as "Some people think they can buy anything" or "When their cards expire so will they !". In fact a very serious matter is being dealt with: the National Health Service, which provides free health care to everyone in the country, can no longer cope. There have been long waiting lists for routine operations for many years, ${ }^{10}$ which is why the two-tier system has developed: more and more people, if they can afford to do so, take out private health insurance so that they do not need to use the NHS. Again, this is a much appreciated fringe benefit if a company provides it, and it is clearly better for the firm if its employees are in good health.

Another cartoon shows the Trades Union Congress, the caption consisting of the TUC's motto: "One member. One vote" ( $n^{\circ} 14$, see Appendix). What is surprising is that the platform is empty and the audience consists of.... one member. Once more, this exaggeration highlights a very real fact: the decline of the influence of the trade union movement in Britain, which can be largely attributed to Margaret Thatcher's determination to "break the unions". Indeed, between 1979, when she became Prime Minister, and 1992, two years after her resignation, the percentage of trade union members fell from $54 \%$ of the working population to $38 \%$ (Ayasch 1996: 178).

\section{Conclusion}

It has been seen that using cartoons as a teaching aid creates conditions that encourage learning: in fact, Oxford, working on the identification of good language learning strategies with a view to showing teachers how to train their pupils to apply them, advocates the use of humour as a way to reduce anxiety -and pictures as a mnemonic strategy (Cyr 1998 [1996]: 31-32). It is interesting to note that the power of the visual memory was recognised as far back as Antiquity, the reason why images (drawings, photographs and mental images) are memorised so well probably being that they are coded both visually and verbally (Lieury, 1993: 55-56), the association of the two being inevitable as soon as concrete thought is involved. Indeed, for psychologists, it is clear that there is a continual interaction between the visual and the verbal in all learning and memorisation processes (Kibédi Varga 1989: 91). It is therefore legitimate to maintain that some of the more unusual cartoon drawings (the carrot contraption, the cleaning machine, the toddlers surrounded by dogs...) will remain associated in some students' minds with the terms and expressions accompanying them or the facts they represent. 
true that a link between the use of cartoons and second language acquisition has yet to be formally proved. Nevertheless, any teaching material that combines the multiple uses of pictures with the pleasure of smiles, laughter and 'getting the joke', clearly deserves to be taken seriously.

\section{BIBLIOGRAPHY}

Ayasch, Isabelle. 1996. La Grande-Bretagne contemporaine. Mémento bilingue de civilisation, $2^{\mathrm{e}}$ édition. Paris: Bréal.

Barthes, Roland. 1964. 1976. "La rhétorique de l'image”. Communications 4, 40-51.

Chapman, Tony \& Hugh Foot (eds.). Humour and Laughter: Theory, Research and Applications. London: John Wiley \& Sons.

Cyr, Paul. 1998 [1996]. Les stratégies d'apprentissage. (Anjou, Québec: Les Éditions C.E.C.) Paris: CLE International.

Forabosco, Giovannantonio. 1992. "Cognitive aspects of the humor process: the concept of incongruity”. Humor 5/1-2, 45-68.

Kaplan, Robert \& Gregory Pascoe. 1977. "Humorous lectures and humorous examples: Some effects upon comprehension and retention". Journal of Educational Psychology 69/1, 61-65.

Kibédi Varga, A. 1989. Discours, récit, image. Liège-Bruxelles: Pierre Mardaga, éditeur.

Lieury, Alain. 1993. La mémoire. Du cerveau à l'école. Paris: Flammarion.

McLaughlin, Barry. 1987. Theories of Second-Language Learning. London: Edward Arnold.

Morin, Violette. 1970. “Le dessin humoristique”. Communications, 15, 110-131.

Morreall, John. 1991. "Humor and work". Humor 4/3-4, 359-373.

Shultz, Thomas R. 1976. “A cognitive-developmental analysis of humour”. In Chapman \& Foot (eds.), Humour and Laughter: Theory, Research and Applications. London: John Wiley \& Sons, 11-36.

Tsui, Amy. 1995. Introducing Classroom Interaction. London: Penguin.

Ziv, Avner. 1979. L'humour en éducation. Approche psychologique. Paris: Éditions ESF.

Ziv, Avner. 1983. "The influence of humorous atmosphere on divergent thinking”. Contemporary Educational Psychology 8, 68-75.

Ziv, Avner. 1988. "Teaching and learning with humor: Experiment and replication”. Journal of Experimental Education 57, 5-15.

\section{NOTES}

1. Humour is used in the very general sense of «the condition of being amusing or comic » ( Oxford Encyclopedic English Dictionary, 1991). 
2. There are two rival theories of humour: the incongruity theory and the resolution of incongruity theory. Whereas some theorists such as Kant, Schopenhauer and Koestler consider that the structure of humour is characterised by incongruity (generally defined as a conflict between what is expected and what actually occurs in a joke), others such as Freud argue that there are two phases in humour appreciation: the discovery of incongruity followed by the resolution of the incongruity. The second phase renders the incongruity of a joke meaningful or appropriate by resolving or explaining it (Shultz 1976: 12).

3. This can take the form of oral participation in class, possibly in groups, or a written assignment.

4. Other examples that could interest ESP teachers are scenes showing doctors and patients, judges and criminals, hotel staff and guests, waiters and diners, computer users and colleagues, etc.

5. As already mentioned, the sexy/stupid secretary is a stock character in this type of document. However, it should be noted that many cartoons show male members of staff in an equally unflattering way.

6. The cartoons given as examples appeared in the Spectator.

7. Cartoon $n^{\circ} 1$ is a good example of the difficulty involved in decoding some documents, since it requires both lexical knowledge (to stash) and cultural knowledge (the fact that the channel Islands are a tax haven). Such points need to be carefully monitored by the teacher.

8. The two documents mentioned were published in the Weekly News.

9. In fact there is a further piece to the puzzle: the reference to Johnny Weissmuller, the first actor to play Tarzan on film. Recognition of this is not essential to the decoding process but the notion that all Tarzan actors are called Johnny, perhaps taking on this stage name in memory of their hero, adds to the humour of the document.

10. The fact that the cartoon was published in 1993 shows that this is a long-standing problem. However, the situation has now reached crisis point as it is no longer just patients requiring routine operations who are put on waiting lists : it has been revealed in recent months that heart patients, for example, have died while waiting for treatment.

\section{ABSTRACTS}

The aim of this study is to explore the interplay between the three components of cartoons illustration, verbal text and humour - and assess its implications for language learners. Whereas some illustrations have a relatively minor role, others play a much more extensive part not only in the humour of the documents themselves, but also in the learning process. It is suggested that cartoons can help students to understand and retain both language items and information on the target culture.

L'objectif de cette étude est, d'une part, d'explorer l'interaction entre les trois composantes des dessins humoristiques (image, texte verbal, humour) et, d'autre part, d'évaluer les effets qu'elle produit sur les apprenants de langues. Alors que certaines images jouent un rôle relativement mineur, d'autres ont une fonction beaucoup plus étendue non seulement dans l'humour de ces documents, mais aussi dans l'apprentissage. En effet, nous tenons que les dessins humoristiques peuvent aider les étudiants à comprendre et à retenir des éléments langagiers ainsi que des informations sur la culture cible. 
INDEX

Mots-clés: anglais des affaires, apprentissage des langues, dessin humoristique, humour, image

Keywords: cartoon, English for business, foreign language learning, humour, image

AUTHOR

PAULINE TEE ANDERSON 